\title{
Analysis and Simulation of Forced Ventilation in Special Condition
}

\author{
Miroslav Rimár ${ }^{1}$, Andrii Kulikov ${ }^{1, *}$, Marcel Fedak ${ }^{1}$, and Milan Abraham ${ }^{1}$ \\ ${ }^{1}$ Technical university of Kosice, Faculty of Manufacturing Technologies with a seat in Prešov, \\ Bayerova 1, 08001 Prešov, Slovak Republic,
}

\begin{abstract}
The research subject of the current work is heating of the closed area by the forced air ventilation system with heat recovery ventilator and floor radiators. The simulation model was made in ANSYS Fluent 14.0. In the simulation were taken to account the secondary thermal gains from the computers, monitors and humans. The results of the simulation approved that in the modern thermal passive houses heat balance calculations should observe secondary thermal gains from the installed equipment. Also were investigated the air circulation in the closed area and the influence of the different barriers which were installed in the laboratory.
\end{abstract}

\section{Introduction}

Nowadays air ventilation plays the great role not only for the human health but also for heat balance calculation of the building. But too hot or cold outdoor air makes interior parameters uncomfortable for some time periods. It is very difficult to build modern passive house without installing air recuperation systems or Heat recovery ventilators (HRV) [1-8].

In the heat balance calculation, it is necessary to know all heat loses and thermal gains. In a modern passive building the heat loses are small, approximately $2-3 \mathrm{~kW}$ per $100 \mathrm{~m}^{2}$. According to this heat balance calculation should be expand by the thermal gains positions which were not present before, for example heat from the working electrical equipment or human body [9-11].

People lose heat in next proportion:

- $\quad 35 \%$ through heat conduction and convection;

- $35 \%$ through thermal radiation;

- $24 \%$ through evaporation;

- $6 \%$ with breathing.

Nevertheless for the private houses it is still very low figures but in the offices where 23 peoples are working on the computers is enough to change the heat [12-14].

\footnotetext{
* Corresponding author: andrii.kulikov@tuke.sk
} 
In the current article we will simulate the ventilation of the air in the laboratory using of HRV and floor radiators in winter conditions with the impact of the small thermal gains such as computers and human body.

\section{Materials and methods}

Room under the study was a laboratory of the renewable energy sources of the Technical University in Kosice. The technical drawing of the laboratory is on the Figure 1.
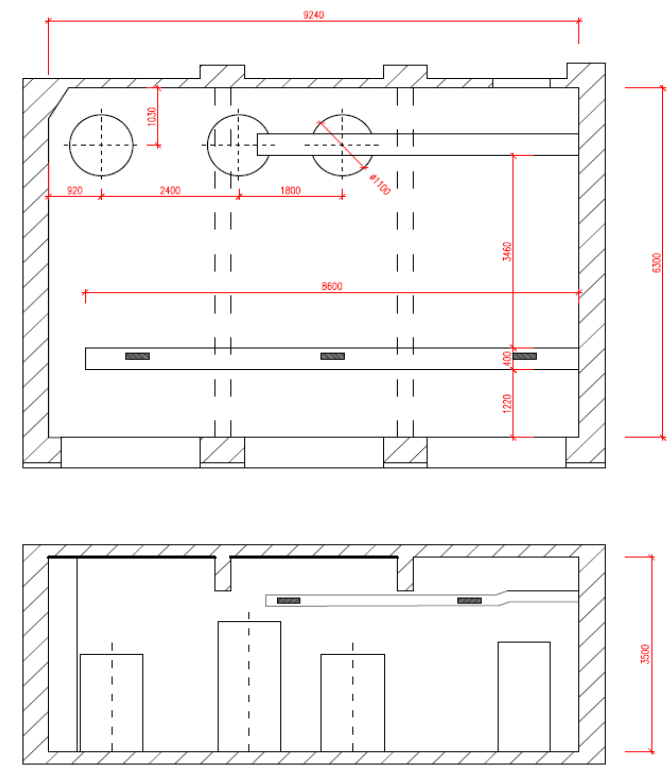

Fig. 1. Laboratory under the study.

In the laboratory there are situated tree thermal storage tanks for the hot and cold water for heating and cooling purposes. The ventilation of the laboratory is going through ventilation canals in the upper part of the room. Fresh air comes to the laboratory via canal 1 and goes out through the canal 2. As you can see from the picture first air canal has two nozzles while the second air canal has three situated approximately at the middle of each the windows. The HRV unit (Sabiana ENY 3) is situated in the room next door. The configuration of ENY 3 allows preheating fresh air in winter period by hot water or integrated electric heater when heat potential of exhaust air is not enough or intensity of ventilation is high.

The regulation equipment is totally controlled by the DESIGO by Siemens. View on the DESIGO program is on the Figure 2.

The input parameters were the same comparing with the article of prof. M. Rimar "Study of gaseous flows in closed area with forced ventilation" (SGFCAFV).

According to EN 12831 the temperature in the laboratory must be $20{ }^{\circ} \mathrm{C}$.

Thermal characteristics of the windows, walls, floor and ceiling were chosen according to their technical documentation.

Sickness of internal walls is $200 \mathrm{~mm}$ and temperature is $22^{\circ} \mathrm{C}$.

External wall has $500 \mathrm{~mm}$ sickness and temperature in the middle of the wall is $18^{\circ} \mathrm{C}$.

Sickness of windows is $100 \mathrm{~mm}$ and external surface temperature is $12{ }^{\circ} \mathrm{C}$.

Celling and floor have $300 \mathrm{~mm}$ sickness and $22{ }^{\circ} \mathrm{C}$ temperature. 


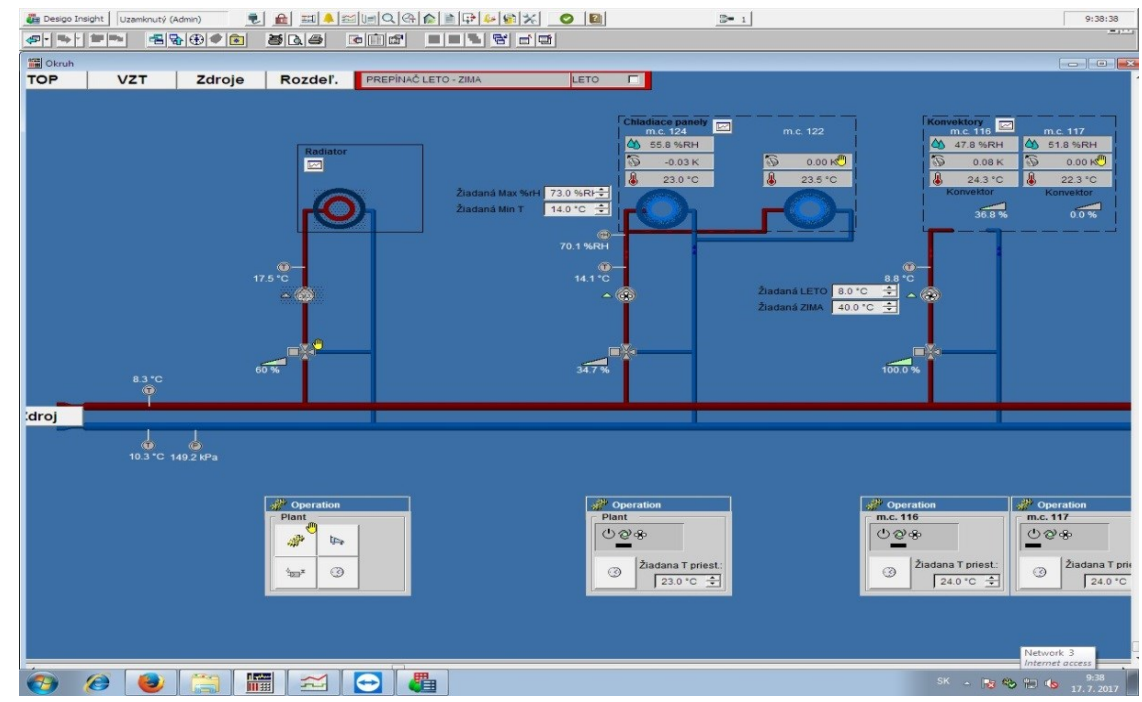

Fig. 2. DESIGO program.

The main source of heat in the laboratory is two floor radiators which are installed under the windows. The surface temperature of radiators is $42-45^{\circ} \mathrm{C}$ in winter period. It is impossible to complete turn off the heating of the laboratory as through this flor radiators is going the whole heat to the building. Also heat achieved through the thermal storage tanks. The tanks are isolated by special fibrous material of $10 \mathrm{~cm}$ sickness. The surface temperature during the day of the first tank (in the corner) is around $24.5{ }^{\circ} \mathrm{C}$, second $23.5^{\circ} \mathrm{C}$, third $-22{ }^{\circ} \mathrm{C}$. The temperature of hot water inside the tanks is approximately $37.5^{\circ} \mathrm{C}$ for the first tank, $32{ }^{\circ} \mathrm{C}-$ second, $25{ }^{\circ} \mathrm{C}-$ - third. Also at the picture you can see six tables with computers and monitors. Computer boxes which are situated under the table are the working station so they have higher energy consumption and as a result higher thermal gains - $100 \mathrm{~W} / \mathrm{m}^{2}$. This parameter was chosen to simplify the simulation model. The thermal gains from the monitors are $50 \mathrm{~W} / \mathrm{m}^{2}$. Two cube models in front of the tables are the simplified models of the sitting human bodies. The surface temperature of the human model was $36^{\circ} \mathrm{C}$.

$3 \mathrm{D}$ model was made in ANSYS design modeler to provide stable calculation and to eliminate inaccuracy in the geometry. ANSYS mesh solver was chosen for the mesh making purpose to reach the better quality. Proximity and curvature advanced size function with fine relevance center, active assembly initial size seed, high smoothing and slow transition also was used for these purpose. According to the settings model had 2,958,471 elements what is by $45 \%$ higher comparing the model without tables, computers and people.

\section{Simulation}

Simulation of the heating and ventilation was made in ANSYS Fluent 14.0. As a setting for FLUENT was used energy equation model, standard K-epsilon model and radiation $\mathrm{p} 1$ model. Inlet type was chosen as velocity-inlet with velocity magnitude $0.2 \mathrm{~m} / \mathrm{s}$ and $19{ }^{\circ} \mathrm{C}$. For outlet was pressure outlet type. All the parameters were chosen according to the technical documentation of the HRV and the norm of the thermal comfort. The research of the heat recovery parameters of the ENY 3 is not a purpose of the current work. The results 
of the simulation are on the picture. At the picture illustrated the streamlines of fresh inlet air ant temperature contours of the laboratory (Figure 3).

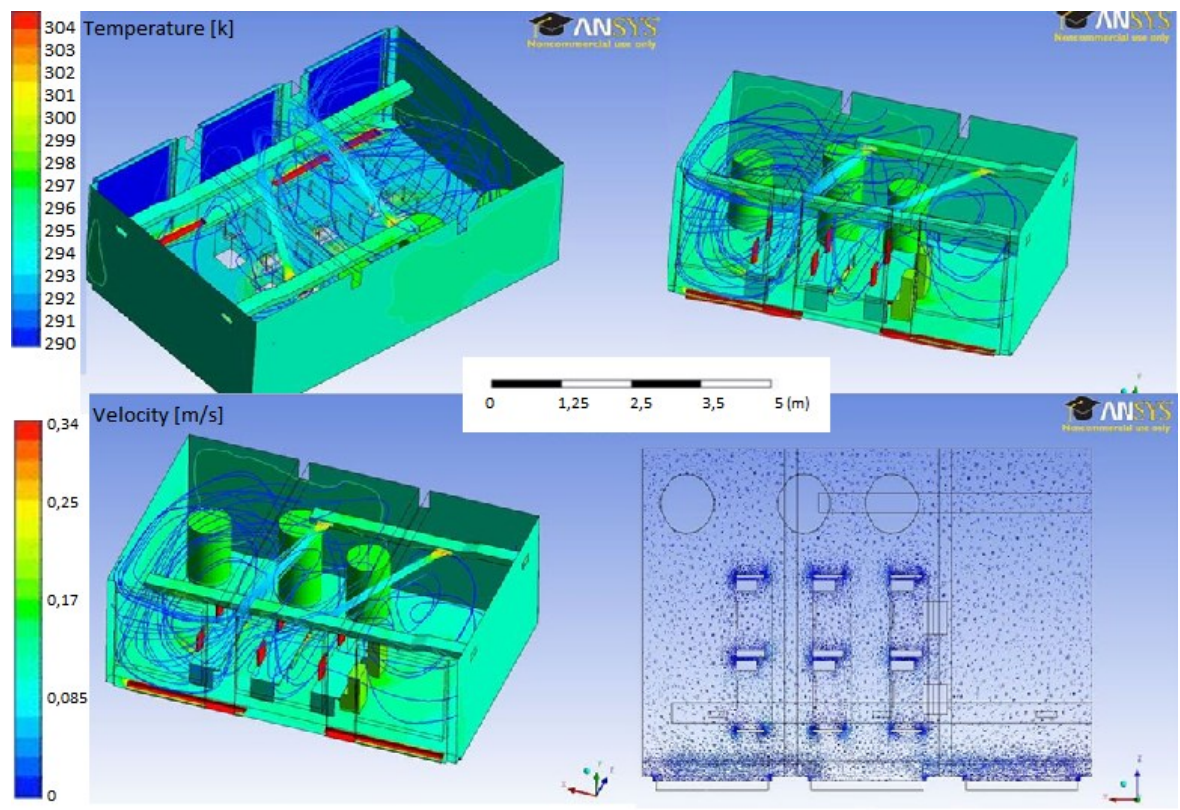

Fig. 3. Results of the first type simulations.

These simulations confirm the results of the previews research SGFCAFV. The main reasons of the turbulent stream at the half of the laboratory are the shape of the nozzles and the ventilation canal also as a velocity of the air. The maximum velocity of the fresh air is $0.36 \mathrm{~m} / \mathrm{s}$ what is under the limits of EN 12831. At the down part of the picture illustrated temperature contours of walls, windows and floor radiators.

Comparing with the model in the previews article SGFCAFV current model has some differences in the down half of the laboratory. This is caused not only by presence of the barriers like tables and humans but also and extra heat sources like computer and monitors. The temperature difference in the vertical axis of the room is $0.7^{\circ} \mathrm{C} / \mathrm{m}$ what is appropriate according to the EN 12831.

Relatively warm fresh air from the HRV comes to the upper part of the laboratory. It encounters to the cold windows and fall down as its temperature reduce. In the down part of the windows warm air near radiators mixing with falling cool air. Than air flow divides by two streams. The first one (warmest) goes up and after mixing with warm extract air exhaust through outlet canal. The second one (coldest) circulate in the down part of the laboratory where it cooling the computers and monitors and after it heats goes up through outlet canals.

According to the simulation the internal temperature in the laboratory is $23-24{ }^{\circ} \mathrm{C}$ depending on the high. The internal temperature according to the thermometers is $24{ }^{\circ} \mathrm{C}$. The difference between the values is caused by the fact that when was set the parameters of wall heat transfer were not consider with thin layers of the wall like paint. The surface temperatures of the computers and monitors are $45^{\circ} \mathrm{C}$ and $41^{\circ} \mathrm{C}$ respectively.

Also was made simulation of the air ventilation in the laboratory with turned off the heating from radiators (Figure 4). 


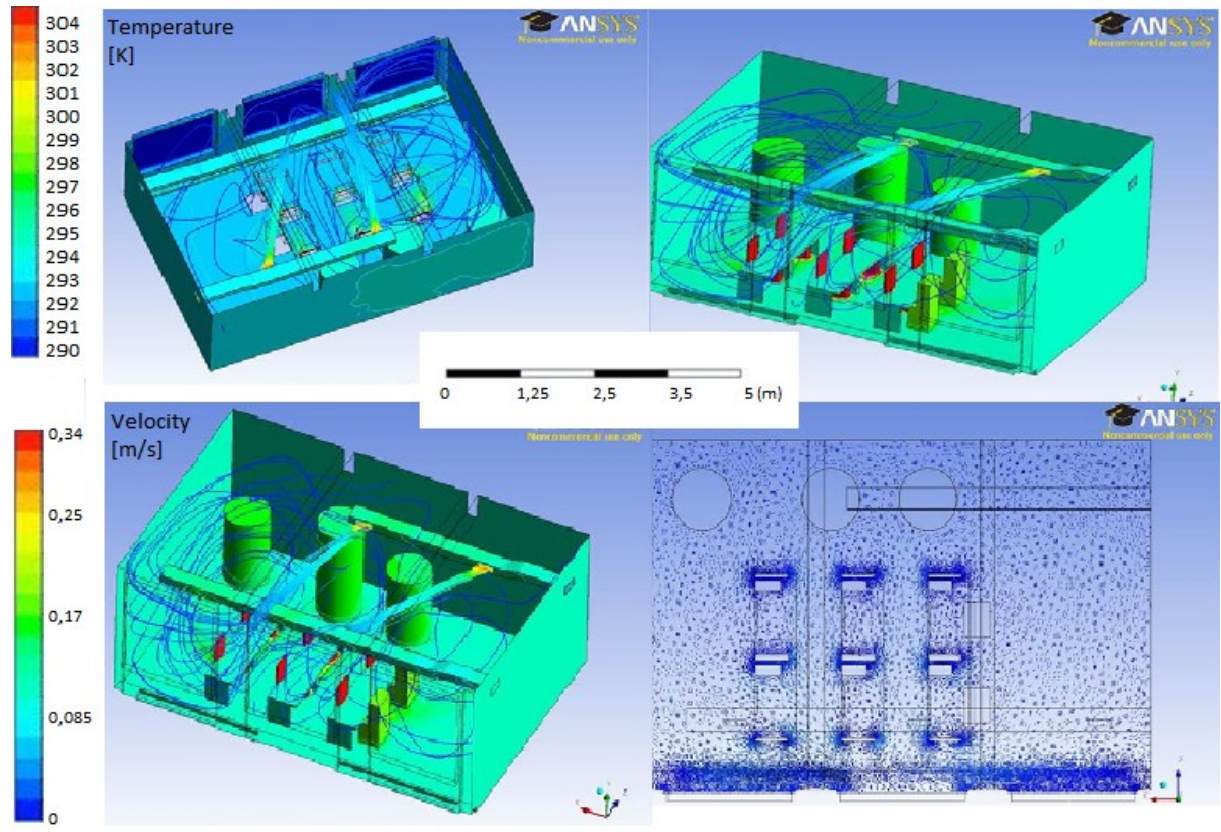

Fig. 4. Results of the first type simulations.

According to this simulation the internal temperature in the laboratory is $21.5-23.4{ }^{\circ} \mathrm{C}$ depending on the high. Such slight difference between the values in the first and second simulations is caused by the thermal gain from the next rooms. The temperature difference in the vertical axis of the room is $1.1{ }^{\circ} \mathrm{C} / \mathrm{m}$ what is very close to the limit according to the EN 12831. Reduction of the internal temperature in the laboratory result slightly changes of the air ventilation. The main trends of air circulation are not changed but the path of the coldest air in the down part of the laboratory increased approximately by $15-20 \%$. Also the surface temperatures of the computers and monitors are decreased by $10-15 \%$ to $42{ }^{\circ} \mathrm{C}$ and $37{ }^{\circ} \mathrm{C}$ respectively.

Comparison of the simulation results of the laboratory model with and without tables, computers, monitors and humans is on the figure (Figure 5,6).

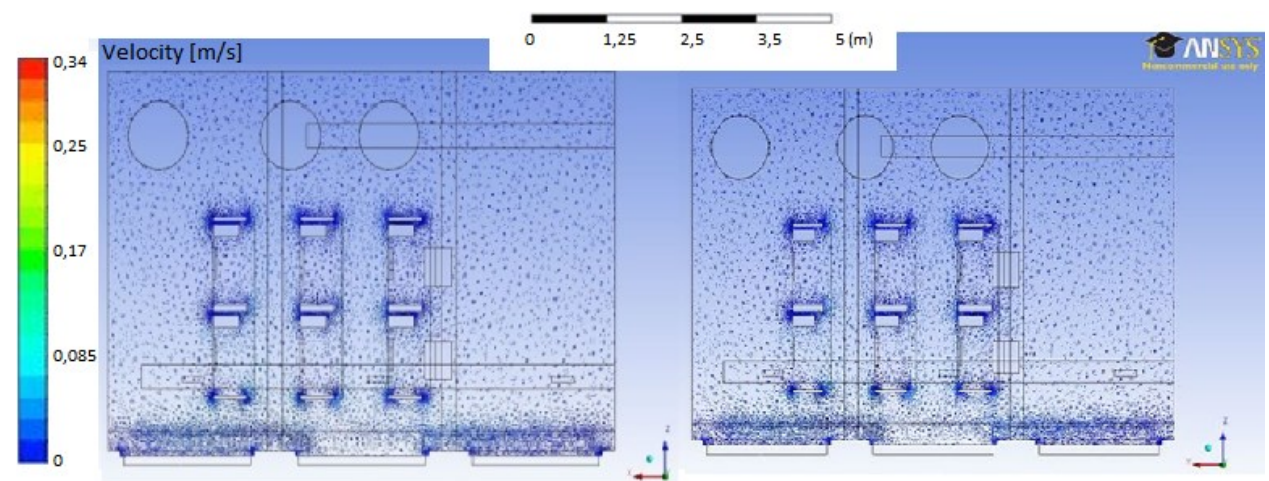

a (floor convectors turned off)

b (floor convectors turned on)

Fig. 5. Air flow in the laboratory with barriers. 
Air circulation in the down part of the laboratory changed significantly in the model with tables, computers, monitors and humans. Figure 5 presents turbulent flow in the down part of the room. This flow is caused by the barriers which are situated on the air flow path.

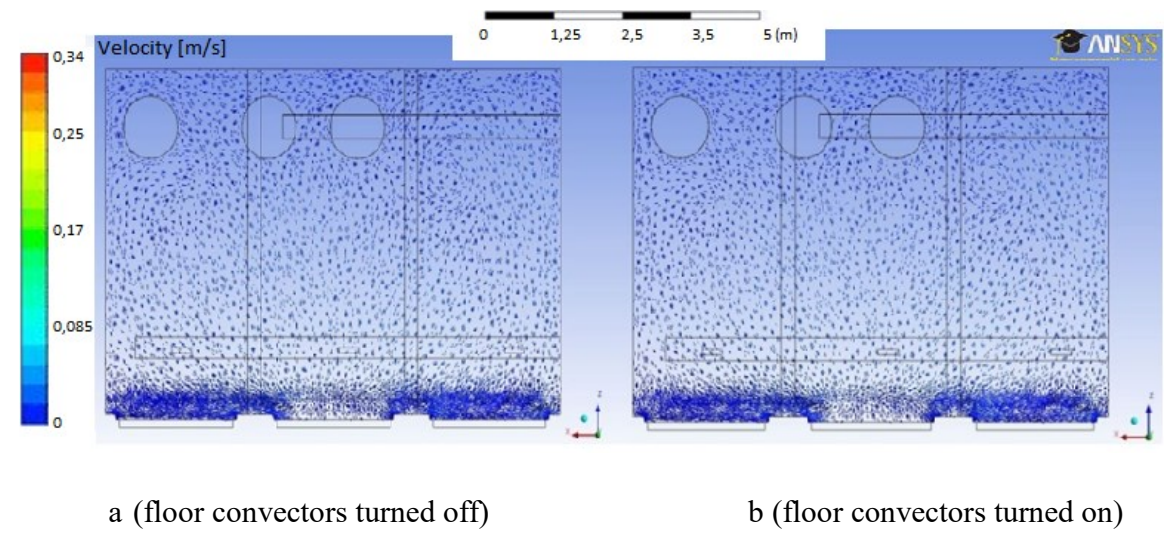

Fig. 6. Air flow in the laboratory without barriers.

Figure 6 presents air flow in the laboratory without barriers. After the turbulent zone near the windows air flow stabilize and has laminar character of the flow.

\section{Conclusions}

The main idea of the current work was to make simulation and analysis of the influence of the secondary thermal gains in the room on its total heat balance system. Secondary thermal gains in the room under the study were computers, monitors and humans. Also was made an analysis of the air ventilation system with heat recovery ventilator. The conclusions of the study are as follows:

- In the modern buildings which belong to the energy passive standard is necessary to take into account with the secondary thermal gains like computers, monitors or other equipment that produces a waste heat;

- Were confirmed the results of the previews research that heating of the room by the only heat recovery ventilation results higher (more than $2{ }^{\circ} \mathrm{C}$ ) differences of the temperature in the vertical axis of the room;

- It is necessary to use modern simulation programs to calculate internal climate of the room as one of the major factor which affect the effectiveness of the work in the closed areas with forced ventilation.

This work was supported by the Slovak Research and Development Agency under the contract No. APVV-16-0192

\section{References}

1. S. Driss, et al., Energy and Buildings (2016)

2. P. Kalliomaki, P. Saarinen, W. Tang J., H. Koskela, Building and Environment (2016)

3. A. Panda, et. al., Applied Mechanics and Materials (2014)

4. J. Zajac, I. Čorný, Monitoring of processing fluids (2004)

5. D. Micallef, Energy and Buildings (2016) 
6. C. Zhang, P.K Heiselberg, Building Simulation (2017)

7. T.H. Pedersen, K.U. Nielsen, et al., Building and Environment (2017)

8. K. Hu, Q. Chen, Building and Environment (2015)

9. M. Napp, T. Kalamees, Energy and Buildings (2015)

10. X. Wu, et al., Energy and Buildings (2016)

11. T. Mikeska, J. Fan, Energy and Buildings (2015)

12. M. Flimel, D. Dupláková, Applied Mechanics and Materials (2014)

13. X. Ye, Building and Environment (2017)

14. J. Jandacka, et al., 10th International Conference on EFM (2015) 